\title{
4 Syntax of verb gradation
}

The discussion in chapter 2 revealed that verb gradation is not uniformly expressed across languages. 'German-type' languages use 'd-adverbials' for degree gradation and a distinct set of 'e-adverbials' for extent gradation. 'French-type' languages - on the other hand - use 'd/e-adverbials' both for extent as well as degree gradation. Based on this distinction, the question emerges whether there is a principal difference between the realization of verb gradation in 'German-type' and 'French-type' languages. A second question that arises is: why are the adverbials used for extent gradation in 'German-' as well as 'French-type' languages - also used as adnominal quantity expressions?

I will propose a syntactically based answer to both questions in this chapter. With regard to the first question I will argue that degree and extent gradation are uniformly expressed in both types of languages. The distinction between extent and degree gradation is syntactically reflected in German- as well as French-type languages. For the latter type this results in a syntactic ambiguity of 'd/e-adverbials.' For the second question, I will propose that 'quantity' is uniformly expressed in a certain syntactic configuration. This is independent of whether quantity in the nominal or verbal domain is concerned: which is not surprising given that the same expressions can be used for the expression of nominal as well as verbal quantity.

In 4.1, I will start with a discussion of French beaucoup and argue for the view that it is syntactically ambiguous between an extent and degree use. Two other proposals on the syntax of adverbial beaucoup will be reviewed, before presenting the crucial data that show the syntactic ambiguity of beaucoup. Section 4.2 introduces the syntactic framework - Role \& Reference Grammar - that is used for the analysis. In 4.3, I am concerned with scope relationships, which can be used to explore the syntactic differences between extent and degree gradation. This section also provides a discussion of grammatical aspect, since verb gradation and grammatical aspect 
show interesting scope relationships. A concrete syntactic analysis of degree expressions within the framework of Role \& Reference Grammar will be presented in section 4.4.4. The analysis will concern adverbially used degree expressions as well as adnominally used ones.

\subsection{Syntactic analysis of adverbial beaucoup}

Before presenting my own analysis of the syntax of degree expressions, I want to discuss some previous analyses of adverbial beaucoup. A considerable amount of work has been done on French adverbial and adnominal beaucoup. At this point, I want to briefly mention the discussion of the so-called 'quantification at a distance'-construction (QAD-construction) in French. In a QAD-construction the adnominal quantity expression beaucoup is placed at a distance from to the noun it modifies, which means that it is realized outside of the NP to which it belongs. ${ }^{1}$ This can best be seen by comparing (1a) and (b). In (a) beaucoup directly precedes the NP de livres, which it modifies. In (b) beaucoup is in adverbial position, as argued for example by Obenauer (1984). Nevertheless, beaucoup still modifies the NP, which can be seen by the presence of the partitive article $d e$, which would be replaced by a non-partitive definite or indefinite article if the quantity expression does not modify the noun.

(1) a. Jean a lu beaucoup de livres. Jean has read a lot of books 'Jean has read many books.'

b. Jean a beaucouplu de livres. Jean has a lot read of books 'Jean has read many books.'

(Doetjes, 1997, 252)

Obenauer (1984) argues for a relationship between the possibility of having a $\mathrm{QAD}$-construction and the type of verb gradation - extent vs. degree gradation - that a verb allows. He states that "the verbs that do not allow

Quantification at a distance is not restricted to beaucoup but is also possible with other degree expressions as for example trop 'too much' or peu 'little' (see Obenauer 1984). See Doetjes (1997) for a discussion of the relationship of QAD-constructions with 'floating quantifiers.' 
QAD are those whose meanings impose the 'intensely'-type interpretation for beaucoup, peu, etc., excluding at the same time the 'often'-type interpretation" (Obenauer, 1984, 162). I will not discuss this type of construction further (for a critical discussion of Obenauer's analysis cf. Doetjes (1997) since it is only indirectly related to the analysis of verb gradation..$^{2}$ Instead, I will focus on two other analyses that aim to explain the two different readings of adverbially used beaucoup: I first discuss Doetjes' (1997) explanation of the verbal extent/degree in terms of theta selection (section 4.1.1) and then continue with Vecchiato's (1999) syntactic analysis of adverbial beaucoup (section 4.1.2). The critical examination of these approaches will be the basis for my own analysis in the following sections.

\subsubsection{Doetjes (1997)}

In her work on degree expressions, Doetjes (1997) aims at explaining the cross-categorical distribution of these expressions on the one hand and how the differences in their interpretations arise on the other. In the following, I will concentrate on her explanation of the differences between the three examples in (2). Example (2a) shows that très rather than beaucoup is used for grading adjectives in the positive. How can the distribution of both expressions be explained? The second question, which will be the more important one, is: how do the different interpretations of verb gradation in (b) and (c) arise? What is responsible for getting an extent (frequency) reading in (b) but a degree reading in (c)?

(2) a. Paul est très/* beaucoup malade.

Paul is very/a lot ill

'Paul is very ill.'

b. Paul va beaucoup au supermarché.

Paul goes a lot to.the supermarket

'Paul goes to the supermarket a lot.'

c. Paul aime beaucoup cette pièce de theàâtre.

Paul loves a lot this play of theater

'Paul loves this play a lot.'

Further discussions of this construction can be found in, for example, Vinet (1996) or Bouchard \& Burnett (2007). 
Doetjes claims that beaucoup is not ambiguous between being a frequency and an intensity adverb. Rather, the difference in interpretation results from different scales to which beaucoup applies. If it applies to an intensity scale, a degree reading results. And if the scale is a quantity scale, it leads to an extent reading. ${ }^{3}$ Both types of scales are syntactically related to different theta positions. For intensity scales, Doetjes assumes a grade position (gposition), which is inherently scalar and represents a lexicalized gradable property. Gradable adjectives and verbs do have such a g-position and its saturation results in adjectival, or verbal degree gradation.

The grammatical reflex of a quantity scale is the quantity position (qposition) which can be found in verbs and nouns. Q-positions are not inherently scalar but depend on the referential properties of the nouns, or verbs at hand. In the case of singular count nouns, the q-position is non-scalar, whereas mass and plural count nouns have a scalar q-position. 'Once-only' predicates like write the letter only have a singular interpretation and therefore have a non-scalar q-position. Such predicates do not allow for a plural reading since a single letter (token) can only be written once. Verbal predications that allow for a plural interpretation like go to the supermarket and the verbal equivalent of mass predicates Bach (1986), which are atelic verbs such as sleep and rain, have a scalar q-position. Extent gradation is possible in the event that a verb has a scalar q-position. For atelic verbs a mass-to-count shift is required; otherwise they do not induce a criterion for counting events (cf. Abeillé et al. 2004, 187). For a more detailed discussion of such shifts, see Bach (1986), among others.

Doetjes argues that beaucoup is not categorically restricted as it modifies nouns as well as verbs. But, she states, it is restricted to scalar theta positions, which are either inherently scalar g-positions or scalar q-positions. The fact that beaucoup is not used with adjectives in the positive form is explained by the 'elsewhere condition.' It states that an expression is blocked for a certain context if a more specific expression of that context exists. This is the case with très in French as it is restricted to the positive form and therefore blocks the application of beaucoup. For German, one can argue that the degree expressions sehr and viel show stronger restrictions than beaucoup does. Sehr is restricted to g-positions and viel to scalar

Doetjes (2007) speaks of 'quantitative' and 'qualitative scales' instead of 'quantity' and 'intensity scales' which basically covers the same distinction. 
q-positions. This would explain the complementary distribution of these expressions with respect to verbal degree and extent gradation.

Since the difference between verbal extent and degree gradation is related to the saturation of two different theta positions and therefore two different types of scales, Doetjes does not need to propose a semantic ambiguity of beaucoup. She also does not assume a syntactic ambiguity of beaucoup, but analyzes beaucoup uniformly as a VP-adjunct that can show variable ordering with respect to the VP. ${ }^{4}$ Relying on the examples in (3), she writes: "In French the DQ [degree quantifier] is ordered quite freely with respect to the elements of the VP. The only restriction seems to be that it cannot occur to the left of the inflected verb" (Doetjes, 1997, 118). This seems to hold only for lexical verbs but not for auxiliaries as (3c) shows.
a. *Jean beaucoup voit Marie. Jean a lot sees Marie
b. Jean voit beaucoup Marie. Jean sees a lot Marie
c. Jean beaucoup a vu sa petite sour. Jean a lot has seen his little sister
d. Jean a beaucoup vu sa petite sour. Jean has a lot seen his little sister
e. ?fean a vu beaucoup sa petite sour. Jean has seen a lot his little sister
f. Jean a vu sa petite sœur.
Jean has seen his little sister

Doetjes mentions that beaucoup is flexible in its positioning but does not relate the syntactic positioning to the difference between extent and degree gradation. I will show in section 4.1.3 that the interpretation of beaucoup is constrained by its syntactic position, which speaks in favor of a syntactic ambiguity of the degree expression. This will also be the major point that separates Doetjes' and my analysis. Essentially, I follow her assumption that beaucoup is semantically non-ambiguous and that extent and degree gradation are each related to different scales. But I reject the view that ex-

Abeillé \& Godard (2003) also argue for an adjunct analysis of degree adverbials in French but assume that they are complements and occur to the right of the predicate they modify. 
tent gradation is related to a quantity scale, whereas degree gradation is dependent on an intensity scale. This assumption is too simplistic, since degree gradation can also be related to a quantity scale as the German example in (4) shows. In this example, sehr specifies the quantity of rain that has fallen but not the extent of the event. Therefore, the distinction between quantity and intensity does not coincide with the distinction between extent and degree gradation. The crucial difference seems to be that for extent gradation the quantity scales measure the quantity of an event, i.e., its temporal duration or frequency, whereas in (4) it is the quantity of an implicit argument of the verb, namely 'rain,' which is measured on the quantity scale.

(4) Gestern hat es sehr geregnet. yesterday has it very rained 'Yesterday it rained a lot.'

In the next subsection, I turn to Vecchiato's syntactic analysis of beaucoup, which indicates that there is indeed a syntactic difference between verbal degree and extent gradation in French.

\subsubsection{Vecchiato (1997)}

Vecchiato (1999) is working in the cartographic enterprise (cf. Cinque \& Rizzi (2008) for an overview) that was used by Cinque (1999) for a crosslinguistic investigation of the order of adverbs. Her aim is to cover French degree expressions - such as beaucoup and peu 'little' - within Cinque's hierarchy. Cinque derives a universal hierarchy of adverbs by investigating the relative order of adverbs. This is illustrated in (5) for the Italian habitual adverb solitamente 'usually' and the negative adverb mica. As the examples show, only the order that solitamente precedes mica is acceptable. Based on such pairs of sentences, Cinque $(1999,106)$ derives the hierarchy in $(6)$.

(5) Italian (Romance <Indo-European; Cinque 1999, 4)

a. Alle due, Giannai non ha solitamente mica mangiato, ancora.

'At two, Giannai has usually not eaten yet.'

b. 'Alle due, Gianni non has mica solitamente mangiato, ancore.

'At two, Gianni has not usually eaten yet.' 
(6rankly $\mathrm{MOOD}_{\text {speech-act }}$

fortunately $\mathrm{MOOD}_{\text {evaluative }}$

[allegedly $\mathrm{MOOD}_{\text {evidential }}$

[probably $\mathrm{MOOD}_{\text {epistemic }}$

[once $\mathrm{T}$ (PAST)

[then T(FUTURE)

[perhaps $\mathrm{MOOD}_{\text {irrealis }}$

[necessarily $\mathrm{MOOD}_{\text {necessity }}$

[possibly $\mathrm{MOOD}_{\text {possibility }}$

[usually $\mathrm{ASP}_{\text {habitual }}$

[again $\mathrm{ASP}_{\text {repetitive }(I)}$

[often $\mathrm{ASP}_{\text {frequentive }(I)}$

[intentionally $\mathrm{MOD}_{\text {volitional }}$

[quickly $\mathrm{ASP}_{\text {celerative(I) }}$

[already T(ANTERIOR)

[no longer $\mathrm{ASP}_{\text {terminative }}$

[still ASP continuative

[always $\mathrm{ASP}_{\text {perfect(?) }}$

[just $\mathrm{ASP}_{\text {retrospective }}$

[soon ASP proximative

[briefly $\mathrm{ASP}_{\text {durativ }}$

[characteristically (?) $\mathrm{ASP}_{\text {generic/progressive }}$

[almost $\mathrm{ASP}_{\text {prospective }}$

[completely $\mathrm{ASP}_{\text {SgCompletive(I) }}$

[tutto ASP PlCompletive

[well VOICE

[fast/early $\mathrm{ASP}_{\text {celerative(II) }}$

[again $\mathrm{ASP}_{\text {repetitive }(I I)}$

[often $\mathrm{ASP}_{\text {frequentative }(I I)}$

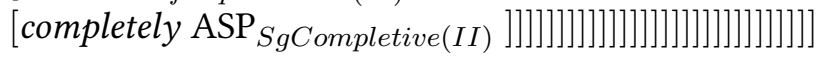

Each semantic class of adverbs, such as 'evaluative mood' or 'durative aspect,' is related to its own functional projection in the clause. Adverbs are analyzed as specifiers of functional heads and have their base position in the specifier position of the respective functional projection. All the different semantic classes of adverbs are strictly ordered with respect to the other classes. 
Vecchiato aims at extending Cinque's universal hierarchy of adverbs by investigating the exact base positions of degree expressions. I restrict myself to her discussion of beaucoup in which she says that it allows for two different interpretations: 'intensity' vs. 'frequentative.' With regard to these two interpretations she states that they "are apparently associated with two different positions in the hierarchy" (Vecchiato, 1999, 262n4). She presents two arguments in favor of the apparent association of beaucoup with two different positions. The first argument is that beaucoup can be realized twice in a sentence. Since each functional projection only has one specifier position, a multiple realization of beaucoup requires that it is related to different functional projections. Vecchiato uses the example in (7) to demonstrate the multiple realization of beaucoup. However, my native speaker consultants rejected the example in (7) as ungrammatical. I will present grammatical examples of multiple realization of beaucoup in the next section.

$$
\begin{aligned}
& \text { La pièce a beaucoup été beaucoup changée. } \\
& \text { the play has a lot been a lot changed } \\
& \text { 'The play has been changed a lot many times. } \\
& \text { (Vecchiato, 1999, 263) }
\end{aligned}
$$

The second argument she raises is that beaucoup in its frequentative reading can occupy more positions in the sentence than if it is used in its degree reading. Vecchiato presents the examples in (8) and (9) to illustrate the differences in the positioning of frequentative beaucoup (8) and intensity beaucoup (9). Following her analysis, beaucoup used as an extent degree expression can directly follow the participle (8b), which is not possible for intensity beaucoup (9b). I will discuss the difference in the syntactic positions extent and degree beaucoup can occupy in more detail in the next section.
a. On a beaucoup discuté ce projet ces dernier 3sG.IPS has a lot discussed this project these latest jours. days 'We have discussed this project a lot of times the latest days.'
b. On a discuté beaucoup ce projet ces dernier jours. 
c. * On a discuté ce projet beaucoup ces dernier jours. (Vecchiato, 1999, 263)

(9) a. On a beaucoup discuté ce projet á la réunion. 3SG.IPs has a lot discussed this project at the meeting 'We have discussed this project a lot at the meeting.'

b. *On a discuté beaucoup ce projet á la réunion.

c. *On a discuté ce projet beaucoup á la réunion.

(Vecchiato, 1999, 264)

Vecchiato uses the methodology employed by Cinque and compares the relative order of adverbs to determine their position in Cinque's universal adverb hierarchy. ${ }^{5}$ For adverbial beaucoup she claims that it is located between tout 'everything' and bien 'well.' ${ }^{\text {T }}$ The examples in (10a) and (11a) are intended to show that beaucoup follows tout but precedes bien, whereas the examples in (10b) and (11b) show that the reverse order results in ungrammaticality.
a. Pierre a tout beaucoup aimé.
Pierre has everything a lot liked
'Pierre liked everything a lot.'
b. Pierre a beaucoup tout aimé.
(Vecchiato, 1999, 271)
a. ?Il a beaucoup bien analysé la pièce de theâtre.
he has a lot well analyzed the play of theater
'He analyzed the play a lot and well.'
b. 'Il a bien beaucoup analysé la pièce de theâtre.
(Vecchiato 1999, 271; slightly adapted)

The examples in (10) and (11) are problematic since in (10) beaucoup is used for degree gradation, whereas in (11) it functions as an extent degree expression. Since Vecchiato claims that frequentative and intensity beaucoup

5 Cinque is not the first person to make use of the relative order of adverbs to explore their syntax. This idea goes back to Jackendoff (1972) and is also used in Van Valin \& LaPolla (1997).

6 Vinet $(1996,215 f$.) argues that in Quebec French beaucoup has to precede bien as well as tout and therefore would occupy a different position in Cinque's universal hierarchy of adverbs which would contradict the claim that there really is a universal and strictly ordered hierarchy of functional heads. 
differ and are apparently associated with two different positions in the hierarchy, the examples in (10) and (11) do not support her analysis. Finally, she claims that there is only one functional projection for adverbial beaucoup, thereby ignoring the arguments she raised for the assumptions that both are related to two different positions in the hierarchy.

Vecchiato presents arguments for syntactic differences of extent and degree beaucoup, but the data she presents are either ungrammatical or inconclusive. In the next section I will present further data that demonstrate the syntactic ambiguity of beaucoup.

\subsubsection{Preliminary observations of the syntactic ambiguity of beaucoup}

In the last section, I reviewed Vecchiato's arguments in favor of the view that extent and degree beaucoup occupy different positions in the sentence. I will build on her arguments and finally conclude, unlike her, that adverbial beaucoup is in fact syntactically ambiguous. The first argument she put forth is that beaucoup can be realized twice in a single sentence. In the last section, I pointed out that my native speaker informants rejected the example Vecchiato gave but there are other examples of a double realization of beaucoup. An example illustrating this point is (12). In this sentence, the frequency of bleeding events as well as the quantity of emitted blood is specified.

$$
\begin{aligned}
& \text { Il a beaucoup saigné beaucoup du nez. } \\
& \text { he has a lot bled a lot from.the nose } \\
& \text { 'He often bled a lot out of his nose.' }
\end{aligned}
$$

There is an explanation why saigner 'bleed' allows for a multiple realization of beaucoup but changer 'change' - the verb used in Vecchiato's example in (7) - does not. Change of state verbs only allow the degree reading of beaucoup but do not license the extent interpretation of beaucoup (cf. Fleischhauer 2013). In (13) beaucoup indicates the degree to which the condition improved but neither its temporal duration nor its frequency. 


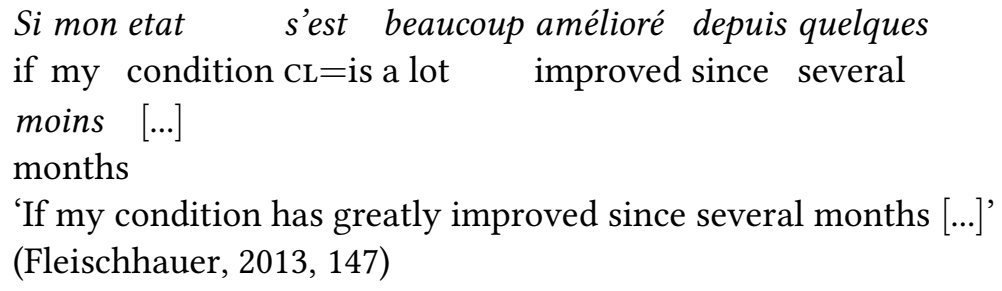

Saigner licenses both the extent and the degree reading of beaucoup. Sentence (14) is ambiguous between the interpretations that the subject referent often bled (frequentative reading), that he bled for a long time (durative reading) or that he emitted a lot of blood (degree reading). A multiple realization of beaucoup is possible if both a degree and an extent reading are available for beaucoup. If a verb licenses only one of these interpretations, a multiple realization of beaucoup is impossible.

$$
\begin{aligned}
& \text { Il a beaucoup saigné. } \\
& \text { he has a lot bled } \\
& \text { 'He bled a lot.' }
\end{aligned}
$$

It can be determined even more precisely which of the two beaucoup's in (12) licences the extent and which the degree interpretation. It is the second, the post participle beaucoup, that specifies the quantity of emitted substance. The first one - placed between the auxiliary and the participle - specifies the frequency of the event. This is shown by the examples in (15). If beaucoup is located between the auxiliary and the participle it can either be interpreted as indicating the extent or the degree (15a). Placed directly after the participle, beaucoup only allows for a degree interpretation (b). And if beaucoup follows the direct object, as in (c), it only gets the extent reading. There is one ambiguous position for beaucoup, which seems to be the preferred one, and two unambiguous positions.
a. Il a beaucoup admiré cette chanteuse à l'opera. he has a lot admired this chanteuse at the=opera 'He has (often) admired this chanteuse (very much) at the opera.'
b. Il a admiré beaucoup cette chanteuse à l'opera. 'He has admired this chanteuse very much at the opera.'
c. Il a admiré cette chanteuse beaucoup à l'opera.
'He has often admired this chanteuse at the opera.' 
The examples in (15) contradict Vecchiato's claim that beaucoup in its degree interpretation is blocked in the position directly following the participle. In fact, example (15b), in which beaucoup directly follows the participle, only allows for the degree reading. In addition, with intransitive verbs the position directly after the participle is restricted to the degree reading of beaucoup (16b), whereas located between the auxiliary and the participle beaucoup is ambiguous (16a).
a. Il a beaucoup saigné $d u$
nez.
he has a lot bled from.the nose 'He bled a lot out of his nose.'
b. Il a saigné beaucoup du nez.
he has bled a lot from.the nose 'He bled a lot out of his nose.'

The frequency adverb souvent is restricted to the position between the auxiliary and the participle and cannot be placed directly after the participle (17). This is not surprising given the synonymy of frequentative beaucoup and souvent.
a. Il a souvent saigné $d u$
nez.
he has often bled from.the nose 'He often bled out of his nose.'
b. *Il a saigné souvent du nez.

Further proof that the position between the auxiliary and the participle is ambiguous, whereas the one directly after the participle is not, is presented in the examples in (18). If one adds the subordinated sentence mais seulement un peu 'but only a little bit' to the sentence in (18a), a contradiction arises. In the main sentence it is expressed that the referent of the subject argument emitted a large quantity of blood, whereas in the subordinated sentence it is expressed that the emitted quantity of blood was merely small. The quantity of blood the subject referent emitted would be specified twice by different degrees. Sentence (18b) is not contradictory since beaucoup is in a syntactically ambiguous position. Ergo, the sentence allows for the non-contradictory interpretation that the referent of the subject argument often bled but emitted only a small quantity of blood. 
a. \#Il a saigné beaucoup du nez, mais seulement un peu. he has a lot bled from nose but only a little bit 'He bled a lot out of his nose, but only a little bit.'

b. Il a beaucoup saigné $d u$ nez, mais seulement un peu. he has bled a lot from nose but only a little bit 'He often bled out of his nose, but only a little bit.'

The data in this section have shown that the interpretation of beaucoup is syntactically constrained. Its position in the sentence determines its interpretation. In section 4.4, I will provide a theoretical explanation of the syntactic differences observed in this section, which will also extend to other languages such as German. The next section introduces the theoretical framework for the analysis.

\subsection{Role \& Reference Grammar}

Role \& Reference Grammar (RRG; Foley \& Van Valin 1984; Van Valin \& LaPolla 1997; Van Valin 2005) is a grammatical framework that attempts to describe and analyze the interplay between form (syntax), meaning (semantics) and communication (pragmatics). RRG - in contrast to e.g. the Minimalist Program (e.g., Chomsky 1995) or Relational Grammar (e.g., Perlmutter 1980) - provides a monostratal account of syntax and therefore only one level of syntactic representation is assumed. A central element of Role \& Reference Grammar is a semantically motivated layered structure of the clause, which is built on the distinction between predicates and arguments on the one hand and between arguments and non-arguments, i.e., adjuncts, on the other hand. The predicate, which can be a verb but also another predicating expression, is contained in the smallest syntactic layer called 'nucleus.' The core, which is the next layer up, contains the nucleus and its arguments. The highest layer is the clause and it contains the core and some optional elements that are not of further relevance for the following analysis. For each layer, there is an optional periphery that contains adjuncts and adverbials. ${ }^{7}$ A further relevant distinction is the one

Throughout this chapter, I use the terms 'adverbs' and 'adverbials' interchangeably for adverbially used expressions irrespective of whether they belong to a lexical class of adverbs or not. 
between constituents and operators. Nucleus, core and periphery are the primary constituents that make up the clause (Van Valin, 2005, 4). Operators are expressions for grammatical categories such as aspect and tense. They are treated as modifiers of different layers of the clause. Two different structural representations for constituents and operators are assumed which are labeled 'constituent projection' and 'operator projection. ${ }^{8}$ Constituent and operator projection are a mirror image of each other and connected through the nucleus. A schematic representation of these structural representations is shown in figure 3.

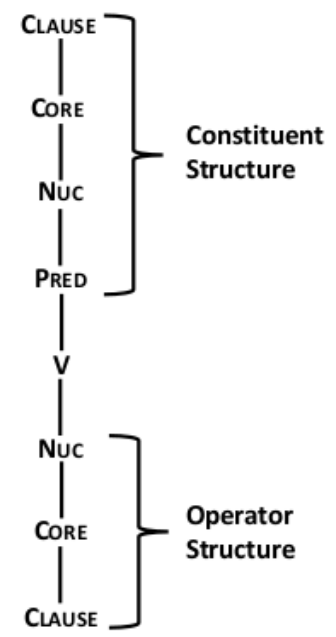

Figure 3: Schematic representation of constituent and operator structure in RRG (following Van Valin 2005, 12).

Two essential differences between RRG and generative approaches to syntax - such as the Minimalist Program or Government and Binding - need to be mentioned. First, there is no notion 'verb phrase' (VP) in RRG. In those languages that seem to have VPs, this is due to a grammaticalization of focus structure (cf. Van Valin 2005, 80f.). Instead of distinguishing between VP-internal and VP-external arguments, RRG locates all the pred-

A third projection - the focus structure - is also assumed in RRG but is not of further relevance for the current discussion. 
icate's arguments equally in the core. Second, RRG does not make use of the traditional notion of 'subject,' since it is not a cross-linguistically valid grammatical function (see Schachter 1976; Van Valin 1980). Instead, RRG employs the notion of a 'privileged syntactic argument' which is not a general grammatical relation but can be specific for certain constructions. For Germanic, Slavic and Romance languages, the privileged syntactic argument corresponds to the traditional notion of subject. For convenience, I continue using the term 'subject.'

Within RRG, adverbs are located in the periphery of the constituent structure and can attach to all three layers of the clause. Although adverbs are uniquely assigned to a certain syntactic layer, it is not assumed that they have a fixed base position (contrary to Cinque 1999, for example). Rather the positioning of adverbs is constrained by the layered structure of the clause. If multiple adverbs are realized in a single sentence, then nuclear adverbs have to be located closer to the nucleus than core adverbs and core adverbs have to be closer to the nucleus than clausal adverbs (Van Valin, 2005, 21). This ordering constraint only holds if the adverbs are located on the same side of the verb, otherwise they cannot be brought into a relative order to each other. In (19) this constraint is illustrated for the English nuclear adverb completely, the core adverb slowly and the clausal adverb evidently. If all three adverbs are located on the same side of the verb, as in (a), then the order has to be evidently $>$ slowly $>$ completely $>$ 'verb.' A different order, as in the other examples except (b), is ungrammatical. Sentences (a) and (b) show that completely and slowly can be placed in the same position, directly in front of the participle. But if slowly is in that position, completely has to be located to the right side of the verb. This indicates that there is no fixed position for these adverbs but that the order of adverbs is only constrained relatively to each other.
a. Evidently, Leslie has slowly been completely immersing herself in the new language.
b. Leslie has evidently been slowly immersing herself completely in the new language.

Note that also the reverse order 'verb' $>$ completely $>$ slowly $>$ evidently is possible, but the relative order of the adverbs remains the same (cf. Van Valin 2005, 20f. for examples). 
c. *Evidently, Leslie has completely been slowly immersing herself in the new language.

d. * 'Slowly, Leslie has evidently been completely immersing herself in the new language.

e. *Slowly, Leslie has completely been evidently immersing herself in the new language.

f. $\quad{ }^{*}$ Completely, Leslie has evidently been slowly immersing herself in the new language.

g. $\quad$ *Completely, Leslie has slowly been evidently immersing herself in the new language.

(Van Valin, 2005, 20)

Even if there is no base position for adverbs in a sentence, this does not mean that syntax provides no constraints for adverbs. One constraint, the relative order of multiple adverbs, has been mentioned above. A further constraint is that the position of an adverb within a sentence may affect its interpretation. This has been demonstrated in the last section for beaucoup and is illustrated for a different example from English in (20). In (20a) cleverly is in the immediate pre-verbal position and the sentence is ambiguous between the following two interpretations: (i) the manner in which Ruth hit the cash was clever or (ii) the fact that Ruth hit the cash was clever. Examples (b) and (c) are unambiguous; (b) only has the first interpretation and (c) only has the second one. ${ }^{10}$ The examples in (20) indicate that operators like the tense operator in English and adverbs interact in such a way that their placement relative to each other constrains the interpretation.
a. Ruth cleverly hit the cash.
b. Ruth hit the cash cleverly.
c. Cleverly, Ruth hit the cash.
(Van Valin, 2005, 20)

In many cases, adverbs and operators function as expressions for the same grammatical category. This, for example, is obvious if one compares the morphological and adverbial marking of tense within and across languages. English uses morphological as well as adverbial devices (e.g., yesterday) for expressing temporal relationships, whereas languages such as Cantonese

$\overline{10}$ This observation goes back to McConnell-Ginet (1982). 
express tense solely through adverbial expressions, as indicated in (21). Tense can also be marked on an auxiliary verb, as the English example in (22) reveals. In this example, the main verb is infinite and tense is merely expressed on the auxiliary. In an RRG analysis, the auxiliary would not be part of the constituent structure but is treated as an operator, indicating among other things - tense.

(21) Cantonese (Sinitic <Sino-Tibetian; Matthews \& Yip 1994, 190) Gwok yììàng yíhchìhn jyuh Sāan Déng.

Kwok doctor before live Peak

'Dr. Kwok used to live on the Peak.'

Peter had left yesterday.

Tense operators are analyzed as clausal operators, whereas Van Valin \& LaPolla $(1997,162)$ consider temporal adverbials to be core adverbs. ${ }^{11}$ This shows that there does not have to be a close match between the layers at which adverbials and their corresponding operators are realized. Furthermore, operators are closed-class items, whereas adverbials form an openclass (Van Valin, 2005, 26n7). But the order of operators is constrained in the same way as the order of adverbs. Nuclear operators are closer to the stem than core operators, which are closer to the stem than clausal operators. A summary of different operators is shown in (23).

(23) Nucleus operators: aspect, negation, directionals (that modify orientation of an action without reference to participants)

Core operators: directionals (that modify the orientation or motion of an participant), event quantification, modality, internal negation

Clause operators: status, tense, evidentiality, illocutionary force (Van Valin, 2005, 9)

Scope relationships of operators are reflected in the logical representation of predications. (24) shows a partial semantic representation of the sentence Has Kim been crying?, which contains three operators. INT(errogativ)

11 It is questionable whether such adverbs as Cantonese yíhchihn 'before' differ from English tomorrow in being clausal operators since they express a relation between speech time and event/reference time which makes them different from English tomorrow and more similar to tense operators. 
expressing illocutionary force, PRES(ent) for tense and PERF(ect) PROG(essiv) as aspectual operators. The scope of operators is reflected in their linear order in the logical structure.

$$
\begin{aligned}
& \left.\left\langle{ }_{\mathrm{IF}} I N T\left\langle_{\mathrm{TNS}} \text { PRES }\left\langle{ }_{\mathrm{ASP}} \text { PERF PROG }\left\langle\text { do'(Kim, }\left[\mathrm{cry}^{\prime}(\mathrm{Kim})\right]\right)\right\rangle\right\rangle\right\rangle\right\rangle \\
& (\operatorname{Van} \text { Valin, 2005, 50) }
\end{aligned}
$$

A relevant factor in the ordering of affixed morphemes is the distinction between inflectional and derivational morphemes. Derivational morphemes are closer to the stem than inflectional ones (cf. Watters 2009, 264 on the impact of the derivational vs. flectional distinction on the order of affixed operators).

With regard to gradation, RRG does not mention an operator that corresponds to degree gradation. But there is one operator that seems to be semantically very close to extent gradation, this operator is called 'event quantification' in RRG. An example for 'event quantification' is provided in (25) from Amele. Amele has the distributive morpheme -ad which expresses a multiplicity of actions in (25a). The corresponding sentence in (b) without the distributive morpheme only expresses a single action.

(25) Amele (Papua-New Guines; Roberts 1987, cited after Van Valin 2005, 11)
a. Age bel-ad-ein.
3PL go-DISTR-3PL-REMPST
'They went in all direction.'
b. Age bel-ein.
3PL go-3PL-REMPST
'They went.'

What the Amele example shows is that the distributive morpheme - the event quantificational operator - is closer to the stem than the tense operator, which is a clausal operator. What is called 'event quantification' by Van Valin is often discussed under the notion of 'pluractionality.'12 $\mathrm{Yu}$ (2003) demonstrates that pluractionality marking in Chechen (NakhDagestanian) may have a frequentative (26a) but also a durative (26b) in-

$12 \quad$ See Armoskaite (2012) and literature cited therein for a discussion of the relationship between verbal plurality and distributivity. 
terpretation, which is quite similar to the different readings of extent gradation that we find.

(26) Chechen (Nakh-Dagestanian; Yu 2003, 293, 299)
a. molu myylu
'drink' 'drink repeatedly'
b. xowzhu xiizha
'ache' 'ache for a while'

The short discussion of the Amele and Chechen data reveals that event quantification/pluractionality can be seen as corresponding to verbal extent gradation. Hence, I consider distributive markers like those in Amele as operators expressing extent gradation. ${ }^{13}$

The Slave example in (27) shows that aspectual operators (in this case inceptive and perfective markers) are closer to the stem than the distributive morpheme $y a$-. Rice (2000), discussing the order of verbal affixes in Athapaskan languages, mentions that the same ordering of distributive and aspectual markers also holds for other Athapaskan languages such as Koyukon, Athna and Deni'ina.

$$
\begin{aligned}
& \text { Slave (Athapaskan; Rice 1989, 678, Rice 2000, 52) } \\
& \text { yá- } d-i j \text { - } t a \\
& \text { DISTR-INCEP-PF-kick } \\
& \text { 'I kicked it many times.' }
\end{aligned}
$$

The data in (25) and (27) reveal that event quantificational operators are affixed closer to the stem than clausal operators, but that nuclear operators like aspect are closer to the stem than event quantificational ones. The described order of operators is in accordance with Van Valin's (2005, 11) claim that event quantification is an operation at the core layer. A second argument for this claim is that the core is the minimal expression and therefore syntactic realization of an event (Van Valin 2005, 11; Bohnemeyer \& Van Valin 2013). Whereas the event predicate is already present at the nucleus layer, the event participants are realized at the core layer. This fits well with Chung \& Ladusaw's $(2004,11)$ claim that at the event level all

13 I do not want to claim that distributive markers solely function as pluractionality markers or expressions of extent gradation as they clearly have other functions too. In Chechen, the pluractionality markers also have a distributive reading Yu (2003). 
arguments except the event argument have to be saturated, which requires a realization of the event participants. Therefore, the lowest layer for event quantification has to be the core.

I argued above that event quantification can be semantically equated with extent gradation. At this stage, I claim that expressions used for extent gradation are realized at the same syntactic layer as event quantificational operators which is at the core layer. Based on this claim, we can formulate the prediction in (28).

(28) Adverbial extent degree expressions are core adverbials.

There are also good candidates for degree operators as the examples from Jalonke in section 2.3 or the Maricopa example in (29) show. Unfortunately, neither the Jalonke nor the Maricopa data allow determining the syntactic layer of the degree operator due to a lack of relevant data.

$$
\begin{aligned}
& \text { Maricopa (Yuman < Hokan; Gordon 1986, 141) } \\
& \text { mhay-ny-sh ny-aham-hot-m } \\
& \text { boy-DEM-SJ 3/1-hit-very-real } \\
& \text { 'The boy hit me hard.' }
\end{aligned}
$$

Within RRG there is no discussion of degree expressions. Van Valin \& LaPolla and Van Valin briefly discuss the adverb completely by introducing the syntactic analysis of adverbs in RRG. But the authors consider completely being an aspectual adverb rather than a degree adverbial. The reason for doing this is that completely conveys the meaning specification of 'completeness' similar to perfective aspect. Since completely is taken to be an adverbial correspondent to aspectual operators, it is analyzed as a nuclear adverb. Such an argumentation cannot easily be transferred to degree adverbials such as German sehr or French beaucoup, which are not that close in meaning to aspectual operators.

Since there is no RRG analysis of degree expressions, we need criteria to decide to which layer expressions used for degree gradation belong. As mentioned above, Van Valin uses the relative order of multiple adverbs as an indication of their syntax. I will not make use of this test criterion since many factors may influence the relative order of adverbs. One relevant factor is information structure. Thus the sentences in (30) show that sehr and the directional PP aus der Nase 'out of the nose' are not uniquely con- 
strained in their relative order. ${ }^{14}$ There is no semantic difference between the sentences in (a) and (b): native speakers of German accept both sentences but prefer the one in (a) due to pragmatic reasons.
a. Er hat sehr aus der Nase geblutet.
he has very out the nose bled 'He bled a lot out of his nose.'
b. Er hat aus der Nase sehr geblutet.
he has out the nose very bled 'He bled a lot out of his nose.'

Maienborn $(1996,2003)$ also mentions that in German the order of locative adverbials is affected by information structure. For an investigation of the relative order of adverbs one needs to take information structure into account but this would go beyond the limits of this thesis. Therefore, my syntactic analysis is based on scope relationships between adverbs and operators rather than on the relative order of adverbs.

\subsection{Scope relationships}

The aim of this section is to demonstrate that expressions used for degree and extent gradation differ in their scope relationships with respect to grammatical aspect. More precisly, extent degree expressions have scope over grammatical aspect, whereas grammatical aspect has scope over expressions of degree gradation. de Swart $(1998,29)$ defines scope informally as "a relational notion, where the interpretation of one expression depends on another one in a certain way." To say that grammatical aspect has scope over expressions of degree gradation means that the interpretation of degree gradation is dependent on grammatical aspect. This is the case if two sentences that only differ in aspect result in two different readings of degree gradation. The same holds for extent gradation having scope over grammatical aspect. If the interpretation of the aspectual operator differs depending on the presence of an extent degree expression, it can be said that extent gradation has scope over aspect. Before I demonstrate that these

$14 \quad$ Van Valin (p.c.) mentions that aus der Nase is probably an argument-adjunct rather than an adverbial. I leave this question open for future work. 
scope relationships hold, I will shortly discuss the formal expression of aspect in Russian, French and German.

\subsubsection{Grammatical aspect in German, French, and Russian}

Grammatical aspect, also called viewpoint aspect by Smith (1997), is basically concerned with the way how a particular situation is described. A basic aspectual distinction can be drawn between perfective and imperfective aspect. The imperfective aspect can itself be subdivided into habitual, continuous and progressive aspect. ${ }^{15}$ This aspectual typology is shown in figure 4 .

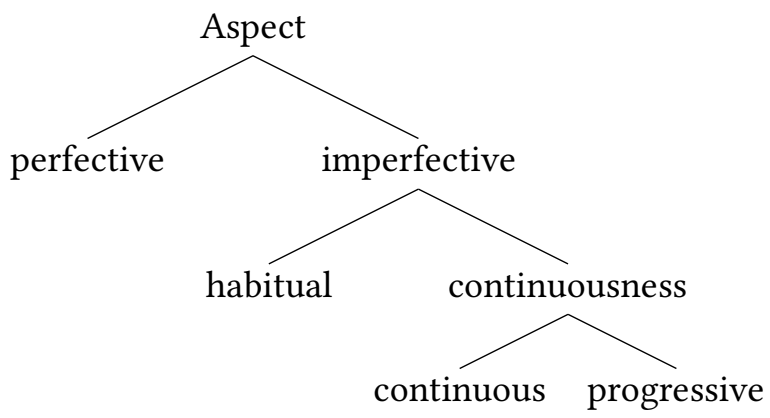

Figure 4: Aspect typology based on Comrie (1976, 25).

By using the perfective aspect, a situation is described as complete but not necessarily as completed. Perfective aspect does not entail resultativity (cf.Comrie 1976), rather it describes a situation as a whole. This means that there is an abstraction from the internal constituency of a situation and neither the end nor the beginning or some other part of the situation is focused on. Imperfective aspect, on the other hand, is used to describe non-complete situations which can be conceived in different ways. With habitual aspect a situation is described as pertaining over an extended period of time" (Comrie, 1976, 27f.). A second major use of the imperfective aspect is to describe situations as ongoing. This can either be done by using a progressive or by using a continuous form. Comrie notes that the

$15 \quad$ Filip \& Carlson (1997), for example, argue against the view that 'habitual' is a subtype of imperfective aspect. 
progressive requires a dynamic predicate and is incompatible with stative predicates. Continuous aspect is conceived by Comrie as semantically close to the progressive but without a restriction to dynamic situations.

German does not have a grammaticalized aspectual system but it has a perfect form like English. As Comrie $(1976,52)$ mentions, the perfect is different from the imperfective/perfective aspectual distinction as it is not concerned with the internal temporal constitution of a situation. Rather the perfect expresses a relation between a situation and a proceeding eventuality. An illustrative example is the resultative use of the perfect as exemplified in (31). In contrast to a plain past tense fohn arrived the perfect form allows the inference that John is still there. "A present state is referred to as being the result of some past situation," as Comrie $(1976,56)$ states it.

\section{John has arrived.}

A resultative reading of the perfect is one use of the perfect form, for a detailed discussion of the perfect see Comrie (1976, chap. 3) and especially Löbner (2002) for a discussion of the perfect in German. I will come back to the German perfect by discussing the expression of aspect in German.

The aspectual system of Russian and Slavic languages in general forces a lot of discussion that I will not review in this thesis (but see Filip 1999). In Russian, all verbs are either perfective or imperfective with some verbs, socalled biaspectual verbs, which allow either a perfective or an imperfective reading. An example of such a biaspectual verb is stabilizirovat' 'stabilize' which is a loan like many other biaspectual verbs. In Russian, there is no distinct marker for perfective or imperfective aspect. We find simplex verbs that are imperfective (32) but also ones that are perfective (33). For the perfective verbs in (33) imperfective simplex verbs exist.
a. znat' ${ }_{\text {IMPF }}$
b. pisat' 'write'
c. govorit' ${ }_{\mathrm{IMPF}}$ 'say' 

a. $\quad$ izičat ${ }_{\mathrm{IMPF}}-i z i c ̌ i t{ }_{\mathrm{PF}}^{\prime}$ 'learn, study'
b. govorit' $_{\mathrm{IMPF}}-$ skazat $_{\mathrm{PF}}$ 'say'

For the examples in (33), it can be said that suppletive stems for imperfective and corresponding perfective verbs exist (33b). But most perfective verbs are derived by prefixation, examples are shown in (34).
a. delat $_{\mathrm{IMPF}}-\mathrm{s}$-delat ${ }_{\mathrm{PF}}$ 'do, make'
b. rezat' ${ }_{\mathrm{IMPF}}-$ raz-rezat $_{\mathrm{PF}}$ 'cut'
c. $\quad$ krast $_{\mathrm{IMPF}}-u$-krast' 'steal'

Verbal prefixes in Russian cannot be considered as inflectional markers of perfective aspect as they quite often change the meaning of the derived verb. An example is shown in (35). Using pro-adds a temporal specification to the base verb but also derives a perfective verb from an imperfective one.
a. '̌itat' ${ }_{\text {IMPF }}$ 'read'
b. pro-čitat' ${ }_{\mathrm{PF}}$ 'read for a while'

Filip (1999, 2000) presents many more arguments for considering verbal prefixes in Russian but also in Slavic languages in general as derivational rather than inflectional affixes. Nevertheless, there is also an inflectional marker of aspect which is the so called secondary imperfective illustrated in (36). The secondary imperfective -(i)va only affects the aspectual interpretation and always yields on imperfective reading of derived and underived perfective base verbs.
a. pisat' ${ }_{\mathrm{IMPF}}$
'write'
b. $\quad$ yy-pisat' ${ }_{\mathrm{PF}}$ 'write out'
c. $\quad v y$-pis-yva-t' ${ }_{\text {IMPF }}$ 'write out/be writing out'


French has a less grammaticalized aspectual system since a systematic perfective vs. imperfective distinction only exists in the past tense. The imperfective past - imparfait - is expressed by an affix that combines information on aspect 'imperfective,' tense 'past' and subject agreement (number and person). Such an imperfective form is shown in (37a). The perfective past is expressed by the so-called pass'e compose which is formed by a present form of the auxiliary avoir 'have' or être 'be' and a participial form of the main verb (37b).
a. nous aim-ions
we love-1PL.PST.IMPF
'we loved'
b. nous avons aimé
we have.1PL love.PARC
'we have loved'

Neither the auxiliary nor the participle can be considered to be the exponent of perfective aspect but both together express temporal, aspectual as well as agreement information. Imperfect is a general imperfective form that can be used for expressing the continuous as well as habitual reading. But there is also a dedicated periphrastic progressive construction formed by the inflected auxiliary être and the form en train de 'in the process of' followed by an infinitival form of the main verb (38).

$$
\begin{aligned}
& \text { Nous sommes en train de rénover norte maison. } \\
& \text { we AUX PROG renovate.INF our house } \\
& \text { 'We are renovating our house.' }
\end{aligned}
$$

German has a periphrastic progressive construction that is somewhat similar to the progressive construction found in French. This form is called rheinische Verlaufsform ${ }^{16}$ which is formed by the inflected auxiliary sein 'be,' a prepositional phrase consisting of a contracted form of the preposition an 'at, on, by' and the dative form of the definite article and followed by a nominalized infinitive. ${ }^{17}$ The form is illustrated in (39).

$16 \quad$ See Andersson (1989) for a discussion of the rheinische Velaufsform and a comparison with other devices for expressing progressive aspect in German.

17 If one takes the presence of the contracted form of the preposition and the definite article seriously, the infinitive should be seen as a nominalized form. This is not accepted by everyone (see the discussion in Andersson 1989) but if one does, it should be reflected in the orthography as in German nouns are written with a capital letter. 

a. Ich bin am Essen.
I AUX at.the.DAT eating 'I am eating.'
b. Ich bin (das) Brot am Essen. I AUX the bread at.the.DAT eating 'I am eating (the) bread.'

Ebert (2000) shows that the use of the progressive form is unevenly distributed in Germany and the form has developed farthest in the Rhineland. In this area (39b) is acceptable, whereas speakers of other areas do not accept transitive verbs in this construction and they accept the combination with a definite direct object even less.

For those speakers who accept the rheinische Verlaufsform, German has a grammaticalized progressive aspect but it still lacks a grammaticalization of perfective aspect. As mentioned above, German has a perfect form which is formed in the same way as the French passé composé by a combination of an inflected auxiliary (either haben 'have' or sein 'be') and a participial form of the main verb. In fact, in many cases - mostly in southern Germany - the perfect simply expresses past tense and it is used instead of the inflectional past tense form. The perfect is not simply reduced to an expression of past tense but still shows up in regular perfect uses. I will not focus on the specific functions of the perfect (in contrast to perfective and imperfective aspect) but take it as a way to force a perfective interpretation. In its non-past but perfect use the perfect form expresses a relation between a situation and a preceeding state. Thereby the situation denoted by the base verb is taken as completed and therefore licenses a perfective reading of the described situation. To be clear, I do not assume that the perfect form in German is a way to express perfective aspect, I merely assume that it can be used to emphasize that a certain situation is described as completed. Nevertheless, the aspectual interpretation is context-dependent as can be illustrated by examples like those in (40) and (41) which are taken from Löbner $(2002,374)$.

$$
\begin{aligned}
& \text { Als ich die } C D \text { gebrannt habe, stürzte der Computer ab. } \\
& \text { when I the } C D \text { burned have crashed the computer PART } \\
& \text { 'While I was burning the } \mathrm{CD} \text {, the computer crashed.' }
\end{aligned}
$$




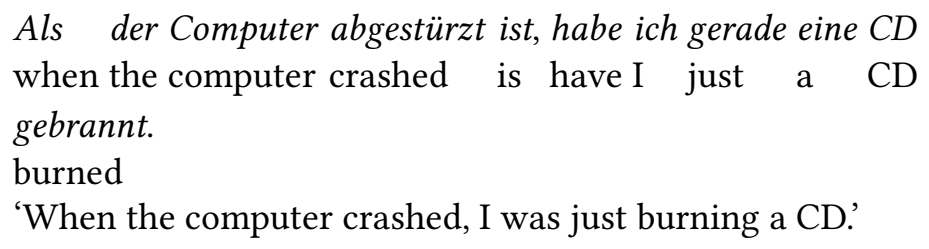

In (40) the perfect shows up in the subordinated sentence and describes the background (what I was doing when something else happened). Both events (the burning of the $\mathrm{CD}$ and the crash of the computer) happened simultaneously and so although the verb is used in the perfect form, the described situation is understood as ongoing. In (41) the subordinate clause as well as the main clause contain a verb used in the perfect form. The main clause describes the background of what I did and therefore receives an imperfective interpretation. The verb used in the subordinate clause gets a perfective interpretation; it does not describe an ongoing event but takes the crashing of the computer as a single whole which is located relative to the burning of the $\mathrm{CD}$.

\subsubsection{Grammatical aspect and verb gradation}

The starting point of this section is Ropertz' (2001) observation that the interpretation of degree gradation interacts with grammatical aspect. The interaction between degree gradation and grammatical aspect is illustrated by the example in (42). In (a) the verb is intended to be used in a perfective context and it shows up in an explicit progressive construction in (b). It is in (a) that sehr specifies the total quantity of rain which has fallen during the event. The interpretation of the (b) example is different, in this case it is not the total quantity of rain that is specified, but the quantity of rain that is falling at a single stage of the event. ${ }^{18}$
a. Gestern hat es sehr geregnet. yesterday has it very rained 'Yesterday it rained a lot.'
b. Es ist sehr am Regnen. it is very at the raining 'It is raining hard.'

18 See Landman $(1992,23)$ on the notion of 'event stages'. 
Both sentences in (42) require different paraphrases. An appropriate paraphrase for (42a) is (43a). The quantity of rain is explicitly specified by the adnominal quantity expression viel 'much'. (43b) is an appropriate paraphrase for (42b); the meaning of the sentence is at best paraphrased by the manner adverbial stark 'strongly, hard.'
a. Gestern ist viel Regen gefallen. yesterday is much rain fallen 'Yesterday, much rain has fallen.'
b. Es ist stark am Regnen. it is strongly at.the rain 'It is raining hard.'

In the perfective as well as progressive case, sehr specifies the quantity of rain. But since the progressive describes an event as ongoing and not completed, sehr cannot specify the total amount of rain. Both readings in (42a) and (b) do not entail each other. That the total amount of rain is large does not mean that at each stage of the event a lot of rain was falling. Rather it is possible that at each stage it rained moderately but the total amount of rain in the overall event amounts to a large quantity. The same holds in the opposite direction: that it rains hard at a certain stage of the event does not entail that the overall amount of rain is large. Rather it could rain hard at a certain short interval but the total amount does not sum up to a large quantity. This would simply be the case if it is raining hard at one stage of the event but only very softly at all other stages. Even if both readings do not entail each other, they are very closely related.

In French, grammatical aspect has the same scope effect on degree gradation as in German. An example similar to the German one discussed above is shown in (44). In the case of a perfective verb (a) beaucoup specifies the total quantity of blood that is emitted during the event. If the verb is used in the progressive aspect (b) beaucoup indicates the quantity of blood emitted at a certain stage of the event.
a. Il a beaucoup saigné.
he has a lot bled
'He bled a lot.'
b. Il est en train de saigner beaucoup.
he is PROG to bleed a lot
'He is bleeding a lot.' 
Only the perfective example in (44a) allows for an extent interpretation of beaucoup. The sentence in (a) is ambiguous between the extent reading that he bleeds often and the degree reading specifying the quantity of emitted blood. The progressive sentence in (b) only licenses the degree reading but not the extent reading of beaucoup. Given the fact that the extent reading requires a multiplicity of events and the progressive describes a single, ongoing event, it is expected that the extent reading of beaucoup is excluded in (44b). This is independent of the position beaucoup occupies in the sentence. As mentioned above, if beaucoup is placed between the auxiliary and the participle, it is ambiguous between a degree and an extent reading. In (44b) beaucoup follows the infinitive, but in (45) it is positioned between the auxiliary and the infinitive. ${ }^{19}$ Also in this case, the only possible interpretation is the degree reading of beaucoup, which demonstrates that aspect constrains the interpretation of verb gradation as an otherwise possible interpretation of beaucoup is excluded in the progressive aspect.

$$
\begin{aligned}
& \text { Il est en train de beaucoup saigner. } \\
& \text { he is PROG a lot bleed } \\
& \text { 'He is bleeding a lot.' }
\end{aligned}
$$

It is not the case that the progressive construction is in general incompatible with verbal extent gradation. This is shown, for example, by the German sentences in (46). In (46a), the degree expression viel 'much' is combined with a verb in a perfective context and with an explicit progressive construction in (46b). In both sentences, viel indicates a high frequency of raining events. This requires a shift from the single event reading of the progressive to an iterative interpretation for (b).
a. Letzte Woche hat es viel geregnet.
last week has it much rained
'Last week, it rained a lot.'
b. Letzte Woche war es viel am Regnen.
last week was it much at.the raining
'Last week, it was raining a lot.'

19 Etre en train de is one constituent and it is not possible for beaucoup to be placed within the construction. 
Comrie $(1976,37)$ discusses a similar case from English which is shown in (47a). He states that in the sentence the reading of the progressive aspect changes towards a habitual reading which happens due to the presence of a lot. Like viel, a lot requires, in its adverbial extent use, a multiplicity of events and therefore is incompatible with a single event interpretation of the progressive. As (b) shows, the interpretation of extent gradation is the same, irrespective of whether the verb is used in the perfect or the progressive form.
a. We're going to the opera a lot these days. (Comrie, 1976, 37)
b. We have gone to the opera a lot.

In the examples in (46) and (47) it is the grammatical aspect that is affected in its interpretation by extent gradation. It was the other way round for the interaction between grammatical aspect and degree gradation. As the German and English data show, the progressive construction is, in general, compatible with extent gradation but for some reason the shift towards a habitual reading of the progressive aspect is blocked for the periphrastic progressive construction in French.

Russian, as a language with a fully grammaticalized aspectual system, shows the same interaction between extent gradation and grammatical aspect as has been observed for German, French and English. Since Russian has a general imperfective aspect, the sentence in (48a) allows for a progressive as well as a habitual interpretation. A further reading, which will be ignored in the following, is that the subject referent has the ability to play guitar. By adding mnogo 'much' to sentence (b) only the habitual but not the progressive interpretation of imperfective aspect is possible.
a. On igraet na gitar-e.
he plays PREP guitar-LOC
'He is playing guitar.' or 'He usually plays guitar.'
b. On mnogo igraet na gitar-e.
he much plays PREP guitar-LOC
'He is playing guitar a lot.'

The data discussed in this section showed that the scope relationships summarized in (49) obtain. Extent degree expressions, or 'd/e-adverbials' used 
for extent gradation, have scope over grammatical aspect, whereas grammatical aspect has scope over degree intensifiers, resp. 'd/e-adverbials' used for degree gradation.

$$
\begin{aligned}
& \text { 'extent' degree expression > grammatical aspect > 'degree' degree } \\
& \text { expression }{ }^{20}
\end{aligned}
$$

In 4.4 , I present a syntactic analysis of verb gradation based on the asymmetrical scope relationships identified in this section.

\subsection{Syntactic analysis of degree expressions}

This section is split into two subsections: I will start with a syntactic analysis of verbal degree and extent gradation and in the second subsection extend this analysis to adnominal quantity expressions.

\subsubsection{Syntactic analysis of verb gradation}

In section 4.2, I predicted that extent degree expressions are core adverbials, since (i) event quantificational operators are analyzed as core operators and (ii) RRG assumes that the core is the minimal syntactic expression of an event. The previous section showed that expressions used for degree gradation and those used for extent gradation differ in scope with respect to grammatical aspect. Extent degree expressions have scope over grammatical aspect, whereas grammatical aspect has scope over expressions used for degree gradation. Aspect, as shown in section 4.2, is a nuclear operator.

Adverbs and adverbials are represented as modifiers in the semantic representation and take different components of these representations as their arguments (cf. Van Valin 2005, 49). In (50) the semantic representation for the verb bluten 'bleed' is shown.

$$
\text { bluten: do'(x, bleed'(x)) }
$$

In (51) the aspectual operator PERF, for perfective aspect, as well as degree expressions are added to the representation. Scope relations are indicated by the angled brackets in the semantic representations. Since aspect has scope over degree gradation, sehr in (b) has to be located closer to the pred-

$\overline{20} \quad>$ ' is used to indicate scope relationships. 
icate than the aspectual operator, whereas the aspectual operator is closer to the predicate than the extent degree expression in (a).

$$
\begin{aligned}
& \text { a. hat viel geblutet: } \operatorname{viel}^{\prime}\left(\left\langle_{\text {ASP } P E R F}\left(\text { do' }^{\prime}(\mathrm{x}, \text { bleed'(x) })\right)\right\rangle\right) \\
& \text { b. hat sehr geblutet: }\left(\left\langle\left\langle_{\text {ASP }} \operatorname{PERF}\left(\text { sehr' }^{\prime}\left(\text { do' }^{\prime}(\mathrm{x} \text {, bleed'(x)) })\right\rangle\right)\right.\right.\right.
\end{aligned}
$$

An operator can have scope over another expression if that expression is on the lower syntactic layer or a syntactic layer further below. As aspect is a nuclear operator and the nucleus forms the lowest syntactic layer, expressions used for degree gradation must be located on that layer too. That expressions used for extent gradation have scope over aspect does not entail that these expressions are located on a specific layer. This scope relationship is compatible with extent degree expressions located at the core or the nucleus layer. But arguments for the view that extent degree expressions are core adverbials have been presented above.

The syntactic representations I assume for extent and degree gradation are depicted in figures 5 and 6 . The tree in figure 5 shows the syntactic structure of the sentence Er hat sehr geblutet 'He bled a lot.' The syntactic structure for Er hat viel geblutet 'He bled a lot' is shown in figure 6. Both trees only differ with respect to the syntactic layer on which the degree expression is located. Scope relationships are not directly visible in the trees but only in the logical representations in (51) above. A note on the representation of grammatical aspect is required. I assume that each sentence has an aspectual interpretation and therefore I assume an aspectual operator present in the syntactic structure of each sentence. But perfective aspect in German is not grammaticalized, so that the operator cannot be linked to a certain element in the constitutent structure. The reason to represent the operator is simply that it shows scope relationships with degree expressions. $^{21}$

Figures 7 and 8 show the syntactic structures for the corresponding French example sentences. Beaucoup in its degree use is shown in figure 7, whereas the syntactic structure for an extent reading of beaucoup is shown in figure 8. There is one major difference to the representation of the German sentences, namely aspect is grammaticalized in the French past tense

21 Van Valin (2008) introduces the notion of a 'referential phrase' (RP) instead of the more traditional term 'nominal phrase' (NP). Nothing in this thesis hinges on this distinction, so I will stick to the more familiar term NP. 


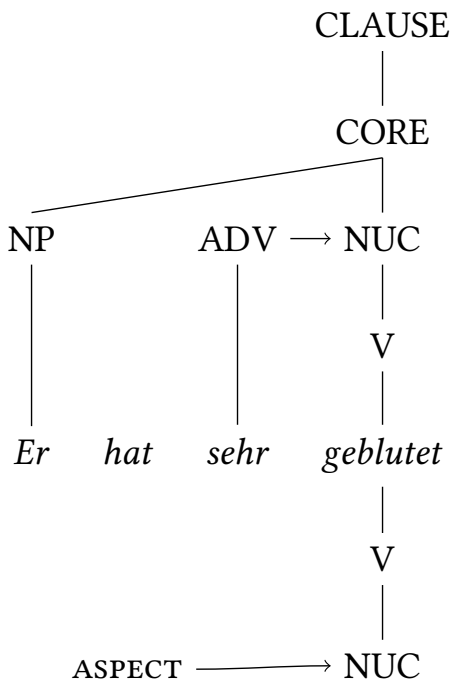

Figure 5: Syntactic representation of degree gradation in German.

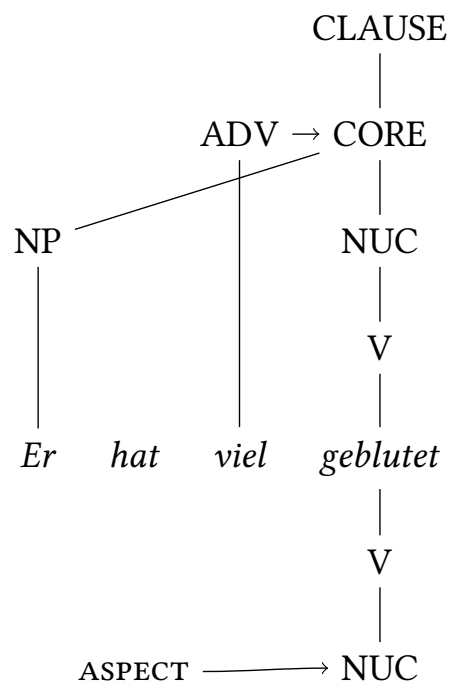

Figure 6: Syntactic representation of extent gradation in German.

and therefore the aspectual operator is linked to an element in the constituent structure. In this case, aspect is contributed by the combination of the auxiliary and the participle. In German, on the other hand, there is no 
overt exponent of the perfective aspect since the perfect construction does not always lead a perfective interpretation but only in certain contexts. Hence, there is no link between the aspectual operator and the auxiliary and main verb in the syntax tree.

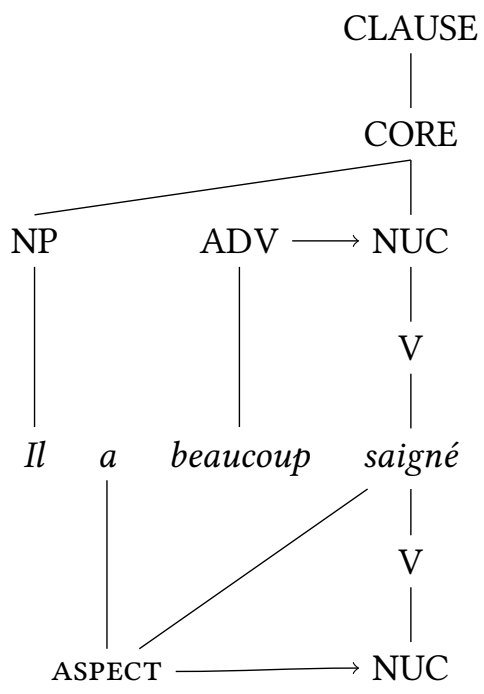

Figure 7: Syntactic representation of degree gradation in French.

Syntactically, degree and extent gradation are related to two different syntactic layers, as indicated by the differences in scope with respect to aspect. This syntactic difference is independent of the fact whether a language uses different adverbial expressions of extent and degree gradation, as German does, or if it uses the same as French. Semantically, this syntactic ambiguity between extent and degree gradation can be explained by relying on different sources that contribute the respective scales for gradation. In case of degree gradation, it is the verb that contributes the scale, whereas for extent gradation the scale is contributed by the event description.

The syntactic analysis presented above does not directly explain the relationship between the positioning of beaucoup and its interpretation as expression of degree/extent gradation. To present a full syntactic explanation of these data, a deeper syntactic analysis of French sentence structure has to be undertaken, which clearly goes beyond the limits of this thesis. 


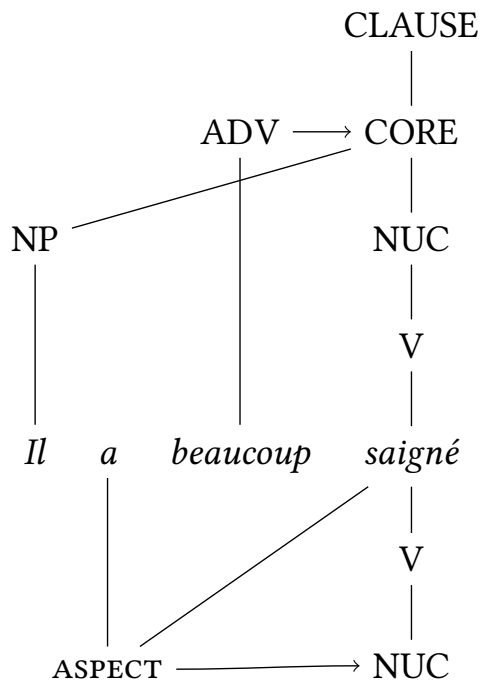

Figure 8: Syntactic representation of extent gradation in French.

\subsubsection{Syntax of adnominal degree expressions}

A central finding of the cross-categorical comparison of degree expressions was that those expressions used for extent gradation also function as adnominal quantity expressions. This holds irrespective of whether a language distinguishes between extent and degree adverbials or not. In addition, it turned out that expressions restricted to degree gradation cannot be used for indicating an adnominal quantity. This section aims in presenting a syntactic explanation for these findings.

I take the RRG approach to noun phrase structures as a starting point of the analysis. In analogy to the layered structure of the clause, Role \& Reference Grammar assumes a layered structure for noun phrases. This structure consists of the layers: nominal nucleus, nominal core and NP. The nominal nucleus is the head noun, whereas the nominal core contains the nucleus and possible arguments of a complex derived noun. The NP-level corresponds to the clause level of the sentence. As in the case of clauses, $R R G$ assumes a periphery for each layer of the noun phrase. There is also a distinction between operator and constituent structure for NPs. Van Valin $(2005,24)$ mentions the nominal operators listed in (52). 

Nucleus operators: nominal aspect
Core operators: number, quantification, negation
NP operators: definiteness, deixis

As for adverbs, adjectives are not conceived of as operators and therefore are not located in the operator structure. Rather adjectives are located in the nominal periphery. Restrictive adjectives, like restrictive adjunct modifiers in general, are located in the nuclear ${ }_{N}$ periphery, whereas non-restrictive ones are placed in the NP-level periphery. The core-level periphery contains "adjunct setting PPs and adverbials of complex event expressions" (Van Valin, 2005, 26). A further similarity between adjectives and adverbs is that adjectives underlie the same kind of ordering constraint as adverbs do: "they [adjectives] must occur closer to the nominal nucleus than core $_{N^{-}}$and NP-level operators and modifiers" (Van Valin, 2005, 26).

The question as to whether adnominal quantity expressions are quantifiers or adjectives has a direct consequence for the syntactic analysis. If adnominal quantity expressions were quantifiers, they would be core operators. But if they are quantity adjectives rather than quantifiers, they would be located in the nominal periphery and not in the operator structure. In the following, I will show that adnominal quantity expressions are adjectives rather than quantifiers.

Starting point for the discussion is the linear order of elements within the German NP. As (53) reveals, a quantifier like einige 'some' is in NP initial position, followed by the definite article, which precedes an adnominal quantity expression as viel 'much'. Other adjectives, like groß 'tall,' follow the adnominal quantity expression and directly precede the head noun.

$$
\begin{aligned}
& \text { einige der vielen großen Kinder } \\
& \text { some of.the many tall children } \\
& \text { 'some of the many tall children' }
\end{aligned}
$$

As Löbner $(1990,42)$ states, adnominal quantity expressions and adjectives occupy different positions within the NP. The examples in (54) demonstrate that the adjective has to follow the quantity expression; the reverse order is not possible. Löbner (1990, 69, also Löbner to appear) states that adjectives have to be in the scope of quantity expressions if they add further sortal specifications to the noun they modify. 

a. viele große Kinder
many tall children 'many tall children'
b. " große viele Kinder tall many children

There is not only a fixed order for quantity expressions and adjectives but also for quantifiers as einige 'some' and vague quantity expressions like viel 'much.' This is shown by the data in (55a) and (b). The quantifier is in NP-initial position, but if no quantifier is present, other elements, such as quantity expressions, can occupy that position (55c).
a. einige der großen Kinder
many the tall children
'some of the tall children'
b. *der einige großen Kinder
the some tall children
many the tall children
'many of the tall children'
c. viele der großen Kinder

In NPs that contain a quantifier as well as a vague quantity expression, the quantifier has to precede the quantity expression. In (56), a definite article in genitive case, expressing partitivity, is placed between the two elements. Only definite articles in partitive function can follow quantifiers and quantity expressions. Non-partitively used definite articles can only precede vague quantity expressions in their cardinal interpretation (57) but not quantifiers (55b) or partitively interpreted quantity expressions.

(56) einige der vielen Kinder some of.the many children 'some of the many children'

(57) die vielen Kinder im Zimmer the many children in.the room 'the many children in the room' 
The order of elements is quite strict and can be summarized as in (58). ${ }^{22}$ This indicates a difference between quantity expressions and quality adjectives on the one hand but also between quantity expressions and quantifiers on the other hand.

Definite Article/Quantifier >Quantity Expression >Quality Adjective $>$ Noun

A further difference between quantity expressions and quantifiers and at the same time a similarity between quantity expressions and quality adjectives can be observed with regard to inflexion. German has different adjective declensions, a weak and a strong one (there is also a mixed declension which I will not mention further). Table 11 shows the two declensions for the plural.

\begin{tabular}{|l|l|l|}
\hline plural & $\begin{array}{l}\text { strong declen- } \\
\text { sion }\end{array}$ & weak declension \\
\hline Nominative & $\begin{array}{l}\text { groß-e Männer } \\
\text { viel-e Männer }\end{array}$ & $\begin{array}{l}\text { die groß-en Männer } \\
\text { die viel-en Männer }\end{array}$ \\
\hline Accusative & $\begin{array}{l}\text { groß-e Männer } \\
\text { viel-e Männer }\end{array}$ & $\begin{array}{l}\text { die groß-en Männer } \\
\text { die viel-en Männer }\end{array}$ \\
\hline Dative & $\begin{array}{l}\text { groß-en Männer-n } \\
\text { viel-en Männer- } n\end{array}$ & $\begin{array}{l}\text { den groß-en Männer- } n \\
\text { den viel-en Männer- } n\end{array}$ \\
\hline Genitive & $\begin{array}{l}\text { groß-er Männer } \\
\text { viel-er Männer }\end{array}$ & $\begin{array}{l}\text { der groß-en Männer } \\
\text { der viel-en Männer }\end{array}$ \\
\hline
\end{tabular}

Table 11: Adjective declension in German, plural forms for the weak and strong declension type.

The weak declension is used if the adjective is preceded by, for example, the definite article. If, on the other hand, the adjective is the first element in the NP or if it is preceded by the indefinite article, the strong declension is used (see Esau 1973 for a discussion of the different adjectival declen-

$22 \quad$ ' $>$ ' is used to indicate linear order, the element on the left precedes the element on the right. The term 'quality adjective' is used instead of plain 'adjective' to indicate that the respective adjectives do not specify the quantity of the head noun. (58) is not exhaustive and does not indicate the relative order of all functional elements within the NP (cf. Löbner to appear for a more detailed discussion of the NP). 
sion paradigms in German). As shown in the table, viel shows the same pattern for weak and strong declension as the quality adjective gro $\beta$ 'tall.' Quantifiers such as einige 'some' only show the strong declension type; the reason is simply that quantifiers are always the first element within an NP. Hence, the difference between weak and strong declension is only used for elements that can be placed in the initial position of the NP and can also be preceded by quantifiers or the definite article.

Based on morphosyntactic concerns, it is reasonable to state that quantity expressions show more similarities to adjectives than to quantifiers (this view is also held by Löbner $(1985,1990)$, Eschenbach (1995) and Solt (2009) among others). Hence, I take them to be adjectives rather than operators. I assume that quantity expressions are realized at the core layer rather than the nuclear layer like quality adjectives. The reason is that quantity expressions are sensitive to nominal number. As the examples in (59) show, viel cannot apply to singular count nouns (a) but only to plural count nouns (b) and mass nouns (c). The mass noun Bier 'beer' is morphologically singular and triggers singular agreement, whereas the plural count noun triggers plural agreement. This is reflected by different declensions of viel in (b) and (c). The mass/count distinction is only relevant with regard to agreement marking, whereas nominal numbers provide a restriction on the applicability of quantity expressions. They require a plural or transnumeral noun, as in (b) and (c).
a. \#viel Mann
much man
b. viele Männer
many men
'many men'
viel Bier
much beer
'much beer'

In RRG, number is considered to be a nominal core operator and since viel is sensitive to number marking, the core operator has to be within the scope of the quantity expression. This is further substantiated by the fact that singular nouns are coerced if they are modified by quantity expressions. Well known examples are those in (60), which are discussed under the label 
of 'universal grinder' (e.g., Bach 1986). In cases like (60), the count meaning of the nouns shifts towards a mass reading which denotes the 'stuff' of car in (a) or missionary in (b). The same holds for cases as (59a), which require coercion due to the singular form of the count noun.

(60) a. Viel Auto für wenig Geld.

much car for little money

'Much car for little money.'

b. Much missionary was eaten at the festival.

(Bach, 1986, 10)

In figure 9, the syntactic representation of the NP die vielen großen Männer 'the many tall men' is shown.

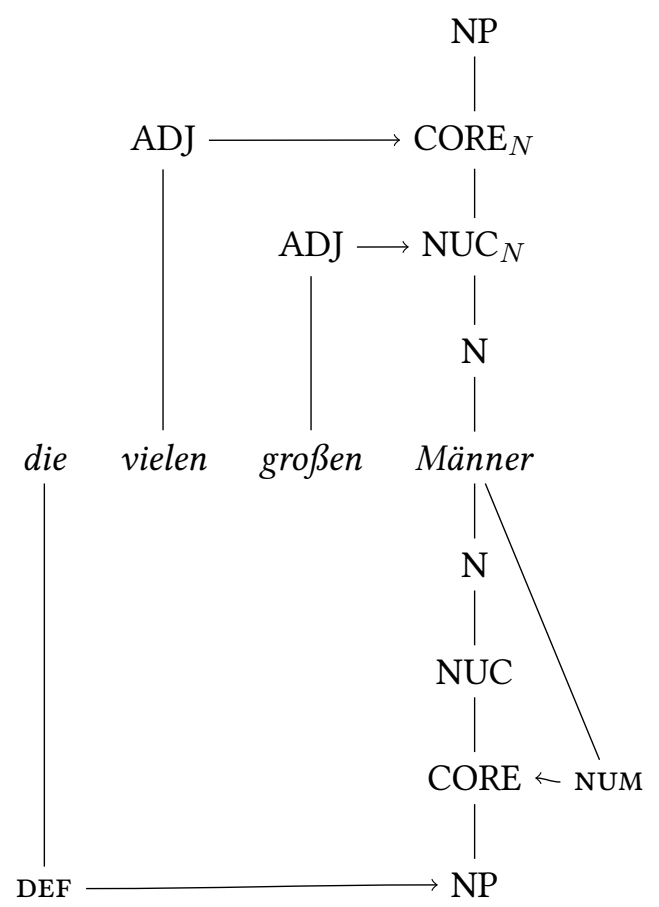

Figure 9: Syntactic representation of the complex NP die vielen großen Männer 'the many tall men'. 
In this section, it has been shown that adnominal quantity is expressed at the nominal core layer. This provides an answer to the question why expressions which are used for verbal extent gradation are also used as adnominal quantity expressions. Extent degree gradation as well as nominal quantity is expressed at the core layer. German viel is not restricted with regard to lexical categories but only with respect to the syntactic configuration it can be used in. It has to be realized at the core layer, which leads to an indication of a nominal quantity in adnominal contexts, whereas it leads to extent gradation in adverbial contexts. Hence, the expression of quantity/extent is done in the same syntactic configuration.

\subsection{Conclusion}

In this section, I argued that the difference between extent and degree gradation is basically a syntactic one. In the case of degree gradation, the degree expression directly modifies the predicate in the nucleus and the scale to which it applies is contributed by the verb. Extent gradation is located at the core layer and the scale is contributed by the event description. The different sources of the scales match with the different syntactic configurations which are used for degree and extent gradation.

As shown in the last section, the syntactic analysis also extends to the nominal domain and can be used to explain the cross-categorical distribution of degree expressions. But it still remains open whether and how the analysis can be extended to the adjectival domain. Is there also a layered structure of the adjective? Van Valin $(2008,172)$ argues that modifier phrases, heading adjectives and adverbs, could have a layered structure too. One of the arguments he presents is that these modifiers can themselves be modified. Besides suggesting such an analysis, Van Valin does not further develop the proposal, which also would surely go beyond the limits of this thesis. More work within RRG on the syntactic structure of adjectival phrases would be required to decide whether the analysis presented above also allows explaining why in languages like German adjectives in the positive take sehr but comparatives take viel as intensifier.

In the next chapter, I turn to the semantics of verb gradation. The results presented in this chapter will be relevant for discussing the (syntax-driven) compositional semantics of verb gradation. 
